\title{
Tataban dan Sunggingan Wayang Golek Menak Yogyakarta
}

\author{
Dewanto Sukistono, Timbul Haryono, R.M. Soedarsono, dan Soetarno* \\ Program Studi Pengkajian Seni Pertunjukan dan Seni Rupa, Sekolah Pascasarjana, \\ Universitas Gadjah Mada Yogyakarta
}

\begin{abstract}
The Sculpture and Painting of Yogyakarta Wooden Puppet. The wayang golek Menak is one of the threedimensional puppet performance in Indonesia. The 'Menak' word indicate that the story was taken from the 'Serat Menak', that's different version with wayang golek Purwa wich taken from 'Mahabarata' or 'Ramayana' story, that was popular in West Jawa. In Yogyakarta, wayang golek Menak was popularized by Ki Widiprayitna about 1950. Based on differences in the source story, then of course there are also differences in the form of puppets, included in the carving and coloration techniques, in Javanesee language is called 'tatahan' and 'sunggingan'. This article intends to reveal the concept of carving and coloration, especially the style of Ki Widiprayitna.
\end{abstract}

Keywords: wooden puppet, Menak, Ki Widiprayitna

\section{Pendahuluan}

Wayang golek Menak adalah pertunjukan wayang golek yang menggunakan Serat Ménak sebagai sumber cerita. Selain wayang golek Menak, di Jawa terdapat beberapa jenis wayang golek dengan sumber cerita yang berbeda, seperti wayang golek Purwa dengan sumber cerita Mahabharata dan Ramayana, wayang golek Wacana Winardi dengan sumber cerita Kitab Perjanjian Lama, wayang golek dengan cerita babad, Panji, maupun yang bersumber dari cerita-cerita lokal di daerahdaerah tertentu. Daerah persebaran wayang golek di Jawa Tengah pada mulanya dapat ditemukan di sebagian wilayah, antara lain terdapat di Tegal, Pekalongan, Pemalang, Brebes, Cilacap, Kebumen, Kutoarjo, Pati, Kudus dan Blora, sedangkan di Yogyakarta terdapat di Kulon Progo, Bantul dan Sleman. Walaupun bentuk boneka secara umum hampir sama, namun tentu saja mereka mempunyai gaya yang berbeda-beda.

Gaya menurut Poerwadarminta berarti cara atau ragam yang mempunyai ciri khusus (Poerwadarminta, 1983: 302). Seperti halnya keaneragaman dalam bahasa dan kebudayaan, keaneragaman seni pertunjukan tidak terbentuk atas dasar pembagian wilayah secara administratif pemerintahan, melainkan atas dasar perbedaan logat dan kebudayaan. Bahkan banyak yang percaya bahwa setiap dalang, dengan garis keturunan tertentu dan berasal dari desa tertentu, akan mempunyai gaya seni pertunjukan tersendiri, tradisi tersendiri, yang oleh para pengamat disebut sebagai gaya atau tradisi lokal (Kayam, 2001: 60). Pengaruh yang paling kuat terhadap permainan dalang ialah kecenderungan dan sifat masyarakatnya sendiri, yang bersamaan dengan itu juga merupakan penonton untuk sebagian besar pergelarannya.

Di dalam pergelaran-pergelarannya dalang mampu melebur sifat-sifat dan keadaan-keadaan khusus masyarakat yang menanggapnya, sematamata karena ia sendiri merupakan salah satu bagian di dalam masyarakat itu. Gaya dalam pengertian tersebut memiliki dimensi kultural, artinya variasi formal di dalam kebudayaan material yang mengandung informasi tentang identitas sosial dan personal. Identitas sosial maksudnya identitas komunal yang menjadi ciri khas pada sosial budaya masyarakat yang bersangkutan. Identitas sosial atau identitas komunal ini disebut emblemic style atau gaya emblem, sedangkan identitas personal disebut assertive style atau gaya asertif. (Wiessner, 1993: 256)

Selama penelitian ini dilakukan belum dapat menemukan sumber tertulis yang mengungkap secara pasti tentang asal-usul keberadaan wayang

*Alamat korespodensi: Prodi Pengkajian Seni Pertunjukan dan Seni Rupa, Sekolah Pascasarjana UGM. Jln. Teknika Utara, Pogung, Sleman, Yogyakarta.55281.Tel. 0274-544975.Email: dsukistono@yahoo.com. 
golek. Di dalam Serat Centhini informasi tentang penciptaan wayang golek dapat dirunut dalam dua bait tembang Salisir sebagai berikut.

(n)Jeng Sunan Kudus iyasa, wayang golék saka wreksa, mirit lakon wayang purwa, saléndro gamelanira. Amung kenong egong kendhang, kethuk kecer lawan rebab, nuju sengkalaning warsa, wayang nir gumuling kisma:1506 (Kamajaya, 1986:201).

(Kanjeng Sunan Kudus [yang] membuat, wayang golek dari kayu, meniru lakon wayang purwa, gamelannya slendro. Hanya kenong, egong kendang, ketuk, kecer serta rebab, ketika tahun sengkalan: wayang nir gumuling kisma. 1506 Jawa atau 1584 Masehi.)

Selain Serat Centhini, di dalam Serat Sastramiruda terdapat informasi sebagai berikut.

Ingkang Sinubun ing Kudus anganggit wayang golék mirit lalakoning wayang purwa, tatabuhané gamelan saléndro, rebab, kendhang, kethuk, kenong, kecèr, egong. Sengkalan: Wayang Sirna Gumuling Kisma:1506. (Kusumadilaga, 1930: 14).

(Sinuhun di Kudus membuat wayang golek, ceritanya meniru wayang purwa, iringannya gamelan Slendro, rebab, kendang, ketuk, kenong, kecer, gong. Sengkalan: Wayang Sirna Gumuling Kisma: 1506 Jawa atau 1584 Masehi.)

Berdasarkan uraian tersebut dapat dilihat bahwa di antara keduanya terdapat persamaan informasi, hanya perbedaannya adalah di dalam Serat Centhini diungkapkan melalui bentuk tembang Salisir dengan sengkalan: Wayang Nir Gumuling Kisma, sedangkan dalam Serat Sastramiruda berbentuk gancaran dengan sengkalan Wayang Sirna Gumuling Kisma. Kata nir dan sirna sebenarnya mempunyai makna atau arti yang sama, yaitu hilang, kosong, dan atau terjemahan lain untuk menunjuk angka 0 (nol). Kata nir barangkali dipakai untuk menyesuaikan jumlah guru wilangan dalam tembang macapat. Brandon juga menyatakan bahwa menurut legenda wayang golek diciptakan Sunan Kudus pada tahun 1584 (Brandon, 2003:65), penggunaan kata 'legenda' dan angka tahun dapat diduga bahwa ia mengacu pada sumber yang sama, yaitu dari Serat Centhini atau Serat Sastramiruda.
Pada periode tersebut di Jawa sudah berkembang boneka tiga dimensi yang berasal dari Cina yaitu wayang Potehi atau wayang Cina (Kwa dalam Kuardhani, 2011:15), oleh karena itu ada anggapan bahwa wayang golek di Jawa dipengaruhi oleh wayang Cina. Holt mengutip pendapat Serrurier dan Sutaarga yang menyebutkan bahwa di antara para pendatang Cina, boneka-boneka bulat rupanya telah dikenal, tetapi boneka-boneka itu boneka-boneka tangan atau marionet dengan tali. Apabila orang Jawa meminjam ide dari boneka-boneka bulat dari Cina, mungkin wajar bagi mereka untuk mengubah teknik-teknik jari atau tali pada kayu, yang dengan itu mereka telah lama mengenal (Holt, 2000: 163).

Namun demikian ditinjau dari bentuk dan teknik, kedua jenis wayang tiga dimensi tersebut sebenarnya sangat berbeda. Wayang golek termasuk jenis rod puppet wayang boneka yang menggunakan tangkai, yaitu sogol untuk menggerakkan badan dan kepala wayang serta tuding untuk menggerakkan kedua tangannya, sedangkan wayang Potehi termasuk glove puppet atau hand puppet yaitu boneka sarung tangan, tidak menggunakan tangkai untuk menggerakkan tangan boneka maupun tangkai untuk menggabungkan badan dan menggerakkan kepala boneka (Currell, 1974: 2-3).

Golèk menurut Snelleman mempunyai dua pengertian, yaitu 'boneka' dan 'mencari'(Snelleman, 1905:406), namun Snelleman tidak menjelaskan secara lebih rinci mengenai hal tersebut. Pemberian arti 'boneka' menunjuk pada sebuah bentuk tiga dimensi yang menyerupai bentuk manusia. Pemberian arti 'mencari' mungkin berasal dari kata Jawa nggolèki yang mengandung arti bulat atau kebulatan. Menurut Poerwadarminta, golèk adalah pepethaning wong sing digawé saka kayu, lan sapanunggalané (bentuk menyerupai manusia yang terbuat dari kayu dan sebagainya); serta ngupaya supaya bisa olèh (berusaha mencari agar berhasil mendapatkan). (Poerwadarminta, 1939: 159).

Sukarno, seorang dalang wayang golek Menak di Yogyakarta menjelaskan bahwa istilah golèk mempunyai makna dadi golèkan (menjadi obyek pencarian). Hal ini mempunyai dua pengertian, pertama adalah mencari makna lakon yang dipergelarkan, kedua mempunyai konotasi negatif yaitu dapat mendatangkan malapetaka. Pencarian 
makna lakon dilambangkan dengan tokoh wayang golek putri atau golèkan pada akhir pertunjukan wayang kulit. Pengertian kedua erat kaitannya dengan kepercayaan atau takhyul, bahwa lakon yang dianggap keramat bahkan pertunjukan wayang golek Menak itu sendiri dianggap dapat menyebabkan musibah, sehingga orang takut untuk menyelenggarakannya (wawancara, 20 September 2009).

Istilah Ménak berarti bangsawan atau luhur (Mardiwasito, 1978: 189). Cerita Menak bersumber dari kesusastraan Persia Qisaa'I Emr Hamza, pada masa pemerintahan Sultan Harun Al Rasyid (Tohir, 1979: 98) yang masuk ke wilayah Melayu pada tahun 1511. Cerita tersebut dikenal sebagai Hikayat Amir Hamzah (Fang, 1982: 151-155) kemudian disadur ke dalam bahasa Jawa dan dikenal sebagai Serat Ménak. Hikayat Amir Hamzah adalah karya sastra Melayu berbentuk prosa yang sangat luas persebarannya meliputi Jawa, Bali, Sasak, Makasar, Sunda, Madura, Palembang, dan Aceh (Istanti, 2005: 1194). Pusat penyebaran agama Islam di Jawa mula-mula di daerah pesisir pantai utara Jawa, di daerah tersebut karya sastra Jawa Pesisiran yang bernafaskan Islam berkembang dalam abad XVI dan XVII.

Di Yogyakarta dan sekitarnya, keberadaan wayang golek Menak dipelopori oleh Ki Widiprayitna hingga mencapai kejayaan sekitar tahun 1950-an. Ki Widiprayitna merupakan keturunan dalang wayang kulit dan sebelumnya juga terkenal sebagai pembuat wayang kulit. Wayang golek Menak Yogyakarta mulai mengalami kemunduran terutama setelah terjadinya pemberontakan PKI pada tahun 1965 karena gejolak politik dan keamanan yang sangat mencekam. Setelah periode tersebut, kenyataannya pertunjukan wayang golek Menak tidak mampu berkembang kembali seperti sebelumnya. Meskipun demikian Ki Widiprayitna tetap bertahan sebagai dalang wayang golek Menak, bahkan ada beberapa pihak dari luar negeri baik dari instansi maupun pribadi yang datang ke rumahnya untuk mencari data dan mendokumentasinya, sayangnya pihak keluarga tidak pernah meminta salinannya. Sepeninggal Ki Widiprayitna pada tahun 1982, maka jejak wayang golek Menak Yogyakarta kemudian diteruskan oleh Sukarno sampai sekarang. Di Yogyakarta dan sekitarnya sampai saat ini jumlah dalang wayang golek Menak sangat sedikit, di antaranya Sukarno dan Suparman dari Kulon Progo, Sudarminto dari Sleman serta beberapa dalang lain yang meskipun mampu mendalang golek Menak tetapi sudah tidak mempunyai lagi koleksi wayang. Minimnya jumlah dalang ini dapat diduga terutama karena wayang golek secara teknis jauh lebih sulit, serta lakon yang tidak akrab sehingga mereka kurang tertarik untuk menggelutinya.

Berkaitan dengan bentuk wayang, Holt mengungkapkan bahwa ikonografi bonekaboneka wayang menandai secara lahiriah peranan fungsional, status hierarkis, dan temperamen, serta kadang-kadang juga usia, keadaan, dan suasana hati. Ukuran bukanlah tanda kebesaran, tetapi lebih pada kekuatan fisik atau keraksasaan, kekasaran serta nafsu yang tak terkendali sebagai yang dipertentangkan dengan penguasaan diri. Pada ikonografi wayang seperti dalam grafologi atau seni membaca karakter melalui tulisan tangan, satu ciri tidak dapat diinterpretasikan terpisah, setiap ciri pasti dihubungkan dengan keistimewaan-keistimewaan penting yang lain untuk sampai pada karakterisasi yang penuh arti. Di dalam wayang ada sejumlah sindrom khas yang elemen-elemen utamanya adalah tinggi, postur, bentuk mata, bentuk hidung, dan termasuk bentuk torso. Ditarik bersama ciri-ciri fisik ini serta sikap-sikap, menandai keadaan jasmani dasar. Peranan serta status fungsional ditandai oleh busana, hiasan-hiasan, serta atribut-atribut (Holt, 2000: 194-195). Berbeda dengan wayang kulit, ikonografi wayang golek tidak sampai pada konsep ikonometri sebagai patokan yang ketat.

Seperti halnya dengan jenis wayang golek lainnya, wayang golek Menak Yogyakarta berbentuk tiga dimensi dengan bahan utama dari kayu. Secara umum bentuk wayang golek dapat dibagi menjadi tiga bagian pokok, yaitu bagian atas yang terdiri dari kepala, bagian tengah terdiri dari badan lengkap dengan tangan, serta bagian bawah berupa kain penutup. Hampir semua tokoh wayang golek memakai baju berlengan panjang tanpa bentuk kaki. Bagian kepala dan badan dihubungkan dengan sogol, yaitu tangkai yang menembus badan. Bagian badan dan lengan dihubungkan dengan tali, termasuk lengan atas dan lengan bawah. Kedua lengan wayang diggerakkan dengan menggunakan tuding atau tangkai yang dipasang pada masing-masing lengan. 


\section{Bahan Baku Wayang Golek}

Wayang golek Menak secara umum terbuat dari bahan kayu untuk bagian kepala, badan, serta tangan. Pada bagian kepala dan tangan biasanya digunakan jenis kayu yang paling ideal yaitu kayu jaranan (dolichandrone spathacea). Jenis kayu ini apabila sudah kering bersifat keras, ringan, berserat halus dan padat tidak mudah menyerap air, tidak mudah pecah serta tidak mudah diserang hama. Kelemahannya bahwa jenis kayu ini pada masa sekarang sangat jarang ditemukan dan pertumbuhannya sangat lambat. Pada bagian badan biasanya digunakan jenis kayu yang lebih ringan, seperti kayu waru (hibiscus tiliaceus), séngon (paraserianthes falcataria), pulé (alstonia) dan sebagainya, sedangkan bagian sogol dan tuding biasa digunakan bahan bambu atau kayu yang keras.

Selain bahan utama kayu, semua tokoh wayang golek Menak Yogyakarta selalu menggunakan pakaian yang terdiri dari dua macam, yaitu baju serta kain penutup atau jarit. Bahan baju inipun disesuaikan dengan tokoh wayang, untuk kalangan atas seperti raja, ksatria, puteri, pendeta, dan sebagainya menggunakan bahan dasar kain jenis bludru yang diberi hiasan berupa manik-manik, serta kain jarit dengan berbagai motif. Tokoh wayang untuk kalangan bawah seperti prajurit, abdi, panakawan dan sebagainya menggunakan kain selain bludru atau bisa juga menggunakan kain bludru tetapi dengan hiasan manik-manik yang lebih sederhana, sedangkan bagian bawah bisa menggunakan jarit atau sarung sesuai dengan kebutuhan.

\section{Bentuk Wayang Golek}

Secara umum, bentuk wayang golek Menak dapat dibagi menjadi tiga bagian pokok, yaitu bagian kepala, bagian badan serta bagian busana wayang. Bagian kepala terdiri dari muka, irahirahan, serta leher. Bagian badan terdiri dari bahu, torso, lengan, serta bokongan, sedangkan busana wayang terdiri dari pakaian (baju, kain/ jarit, sabuk), perabot (keris, pedang, sampur), serta perhiasan (gombyok sumping, anting-anting, kalung ulur, gelang). Semua tokoh dalam wayang golek Menak Yogyakarta menggunakan baju dengan berbagai macam bahan dan perhiasan sesuai dengan tokoh wayang.
Bagian kepala dan bagian badan dihubungkan dengan sebuah tangkai yang disebut dengan istilah sogol dengan bentuknya yang khas, berfungsi untuk memegang dan menggerakkan wayang, khususnya bagian kepala untuk dapat menoleh ke kanan dan ke kiri. Sogol ini dipasang dengan cara menembus bagian badan wayang dari bokongan sampai bahu dalam posisi longgar supaya badan mudah diputar dan bergerak naik turun, serta sebagian leher wayang dengan posisi kencang atau melekat erat agar kepala tidak lepas. Pada bagian tangan dan badan dihubungkan dengan tali, begitu juga pada bagian lengan atas dengan lengan bawah sehingga tangan wayang bisa bergerak bebas ke segala arah. Pada masingmasing telapak tangan wayang dipasang sebuah tangkai yang disebut dengan istilah tuding yang berfungsi untuk menggerakkan wayang.

Bagian kepala secara garis besar dibagi menjadi dua bagian pokok, yaitu bagian muka dan perhiasan penutup kepala atau irah-irahan. Bagianbagian tersebut secara umum sangat dipengaruhi atau bahkan meniru bentuk-bentuk pada wayang kulit purwa yang kemudian disesuaikan dan dibuat ke dalam bentuk tiga dimensi. Motif-motif tatahan dalam perhiasan atau ornamentasi bagian irah-irahan juga meniru dari motif tatahan pada wayang kulit purwa tetapi dengan bentuk yang jauh lebih sederhana.

Bentuk muka wayang golek Menak Yogyakarta apabila diperinci bagian-bagiannya terdiri dari bentuk mata, bentuk hidung, bentuk mulut, bentuk kumis, bentuk janggut, serta bentuk cambang. Bentuk mata terdiri dari tujuh macam, yaitu: 1) gabahan untuk tokoh alusan; 2) kedhelèn untuk katongan; 3) kedhondhongan untuk gagahan, patih, raseksa (raksasa laki-laki) maupun raseksi (raksasa perempuan), Limbuk serta panakawan Jiweng dan Bladhu; 4) kiyip/kriyipan untuk patih Bestak, serta pendeta raksasa; 5) plolongan untuk panakawan Toples; 6) plelengan untuk raksasa; serta 7) penanggalan untuk abdi atau pendeta tua. Bentuk hidung terdiri dari empat macam, yaitu: 1) mancung untuk alusan; 2) sembada untuk katongan bermata kedhelèn; 3) nyanthik palwa untuk gagahan, raseksan, dugangan; dan 4) janma untuk panakawan dan dugangan. Bentuk mulut terdiri dari tujuh macam, yaitu: 1) damis untuk alusan; 2) mèsem untuk alusan dan gagahan; 3) pringisan untuk gagahan; 4) gusèn untuk gagahan; 
5) gusèn tanggung untuk gagahan; 6) prèngèsan untuk raksasa; dan 7) mènjeb, ndomblé, susur, mlecu, serta nyoro untuk dhagelan. Bentuk kumis terdiri dari enam macam, yaitu: 1) Lemet untuk alusan; 2) Lemet luk untuk gecul; 3) Capang untuk gagahan dan rasêksan; 4) Sanggan untuk gagahan dan rasêksan; 5) Sumpel untuk gecul; dan 6) Sapumegar untuk gecul. Bentuk janggut terdiri dari enam macam, yaitu: 1) ukel cekak untuk gagahan; 2) lugas cekak untuk gagahan dan dugangan; 3) lugas tanggung untuk gagahan dan pendhitan; 4) ukel tanggung untuk gagahan dan raseksan; 5) lugas dawa untuk gagahan dan raseksan; serta 6) ukel dawa untuk raseksan. Bentuk cambang terdiri dari lima macam, yaitu: 1) corèkan lugas untuk alusan putran; 2) corèkan ngudupturi untuk gagahan dan pendhitan; 3) seritan ukel untuk gagahan; 4) seritan lugas untuk gagahan dan dugangan; 5) wok untuk gagahan.

Bentuk tata rambut dan penutup kepala atau irah-irahan pada wayang golek Menak Yogyakarta juga banyak meniru pada wayang kulit purwa. Bentuk irah-irahan dan tata rambut ini dapat dibedakan menjadi duapuluh tujuh macam, yaitu: mekutha untuk raja, topong atau tropong untuk raja, topong songkok khusus untuk tokoh Prabu Jenggi, lungsèn tepèn untuk raja dan putran, céwas untuk raja, putran, dan putrén, céwas lungsèn untuk putran dan putrèn, gelung keling untuk raja dan putran, gelung gembel untuk raja dan putran, gelung supit urang untuk raden Iman Suwangsa, gelung kéyongan unyuk putrèn, gelung bokoran untuk putrèn, tekes untuk putran dan putrèn, grudhan atau garudha mungkur untuk putran dan putrèn, serban kéyongan untuk raja atau putran, serban udheng gilig untuk tokoh Umarmaya dan Umarmadi, kanigara untuk tokoh wayang golongan patihan, kanigara nyamat untuk patihan dan dugangan, kethon untuk bala dugangan, iket blangkon untuk bala dugangan, iket udharan untuk bala dugangan, topi (dari kombinasi kulit/kain bludru) untuk Umarmaya, gelung kondhé untuk putrèn, gelung sanggul untuk putrèn, gundhulan untuk geculan, misalnya Toples, kuncung dari rambut asli untuk geculan, khususnya Jiweng, gombak dari rambut asli untuk geculan, khusus untuk Darwis, serta rambut gimbal géndhong dari rambut asli untuk buta babrah.

Bentuk mekutha secara umum hampir sama dengan wayang kulit hanya bagian-bagiannya lebih sederhana. Berbeda pada wayang kulit purwa, pemakaian irah-irahan mekutha pada wayang golek Menak tidak disertai dengan pemakaian praba. Garudha mungkur yang pada masa Jawa Timur berfungsi sebagai atribut bagi raja-raja yang baik, pada boneka wayang kulit dan pada wayang wong diganti dengan simbol-simbol mekutha (mahkota berbentuk seperti helm) dan praba (aureole) (Soedarsono, 1997: 308-309).
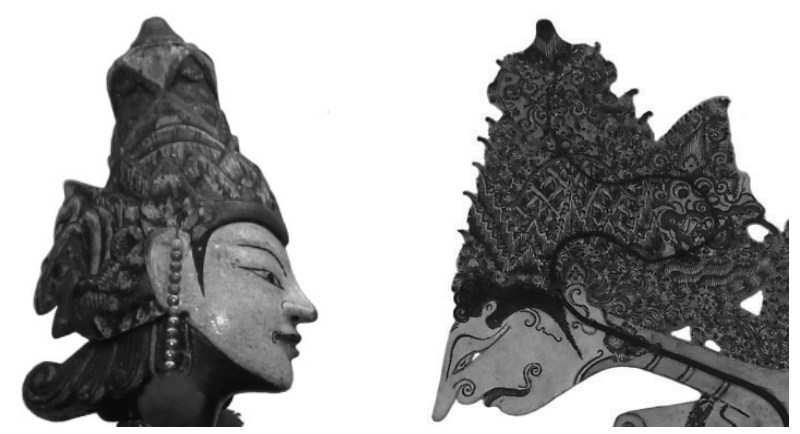

Gambar 1

Bentuk mekutha pada wayang golek Menak Yogyakarta secara umum mengacu pada bentuk mekutha wayang kulit Purwa

(Foto: Dewanto Sukistono, 2009)

Praba tidak begitu banyak digambarkan pada relief-relief bercerita di candi-candi Jawa Timur, tetapi praba merupakan simbol yang umum bagi raja-raja yang baik, pangeran serta puteri yang baik. Bernet Kempers seperti dikutip Soedarsono menjelaskan bahwa praba juga dikenakan oleh Buddha dan Bodhisattwa seperti terpahat di candi-candi Buddha seperti misalnya candi Borobudur dan candi Mendut (Soedarsono, 1997: 309). Pada perkembangannya makna dan fungsi perhiasan mekutha dan praba mengalami pergeseran, karena banyak tokoh-tokoh tidak baik atau jahat juga memakai perhiasan ini, kecuali mekutha biasanya selalu dipakai oleh raja atau tokoh kerajaan lainnya.

Beberapa bentuk irah-irahan tersebut biasanya dilengkapi dengan perhiasan tambahan, seperti jamang, sumping yang menempel di bagian telinga, kanthong gelung, serta gelapan atau bledhègan atau garudha mungkur yang berfungsi sebagai kancing jamang. Bentuk jamang dapat dibedakan menjadi empat macam, yaitu jamang tracap digunakan untuk tokoh raja atau putran, jamang pilis untuk putran atau putrèn, jamang paès untuk putrèn, serta jamang kagok untuk gagahan atau raseksan 
rucah. Bentuk sumping pada umumnya berbentuk mangkara dan mangkaranata. Sumping ini tidak digunakan pada tokoh yang memakai sorban kéyongan, sorban udheng gilig, kanigara, kanigara nyamat, kethon, blangkon, iket udharan, gelung sanggul, gelung kondhé, serta gelung bokoran.

Motif bentuk gelapan atau bledhègan sebagai kancing jamang dalam wayang golek Menak terdapat empat macam, yaitu bledhègan dengan utah-utahan pendek, bledhègan dengan utahutahan panjang, bledhègan dengan ukuran kecil serta motif garudha mungkur dan semua bermata dua. Gelapan dengan utah-utahan pendek digunakan pada tokoh yang memakai irah-irahan céwas lungsèn, mekutha, topong, topong songkok, sedangkan gelapan dengan utah-utahan panjang dipakai pada tokoh yang memakai irah-irahan céwas dan lungsèn tepèn. Gelapan ukuran kecil dipakai pada tokoh yang memakai irah-irahan gelung gembel, gelung keling, serta gelung kéyongan, sedangkan garudha mungkur dipakai pada tokoh yang memakai irah-irahan céwas dan kanigara.

Soedarsono menjelaskan tentang hiasan garudha mungkur bahwa hiasan tersebut telah terdapat pada relief Ramayana di candi Penataran (11981454) di Jawa Timur, dikenakan oleh tokoh Rama dan Sugriwa dan kemungkinan besar dianggap sebagai atribut raja yang baik. Selain itu juga terdapat di reliefbercerita di candi Jago (1268) yang menggambarkan adegan dari cerita Pãrthayajña, hiasan tersebut dipakai oleh Pandhawa bersaudara kecuali Yudhistira; di candi Surawana (akhir abad ke-14) yang menggambarkan adegan-adegan dari cerita Bhomakãwya, serta di candi Kêdaton dikenakan oleh Samba, putera Kresna. Hiasan garudha mungkur berfungsi sebagai hiasan yang memiliki kekuatan melindungi, atau bahkan mungkin dimaksudkan sebagai hiasan biasa pada boneka-boneka wayang kulit dewasa ini. Kanjeng Jayadipura, perancang tata busana wayang wong dari keraton Yogyakarta mengganti nama garudha mungkur menjadi bledhègan atau gelapan (Soedarsono, 1997: 295-296).

\section{Tatahan dan Sunggingan}

Pembahasan tentang tatahan akan terkandung dua pengertian, yaitu persoalan motif dan teknik tatahan. Motif tatahan wayang golek Menak mengacu pada motif tatahan wayang kulit purwa, hanya bentuknya lebih sederhana dan secara umum hanya menggunakan empat macam motif yang disebut pecahan, yaitu mas-masan, inten-intenan, tratasan, serta seritan. Tratasan berupa pahatan atau goresan panjang, hampir sama dengan langgatan dalam wayang kulit hanya bentuknya pendek berjajar. Motif mas-masan terdiri dari mas-masan lugas dan mas-masan pucuk baik tegak maupun miring, motif inten-intenan bentuknya bulat-bulat, sedangkan seritan berfungsi sebagai penggambaran rambut, baik kumis, cambang, maupun rambut kepala. Meskipun motif tatahan wayang golek mengacu pada wayang kulit purwa tetapi secara bentuk jelas berbeda, karena tatahan wayang kulit purwa akan menghasilkan lubanglubang yang menggambarkan tingkat kerumitan dan keindahannya, baik secara langsung maupun yang terungkap lewat bayangan di kelir. Tatahan pada wayang golek tidak menghasilkan lubang, motifnya lebih sederhana karena hanya berfungsi untuk memberikan ruang pada motif warna atau sunggingannya saja, oleh karena itu detail bentuknya tidak terlalu dominan.

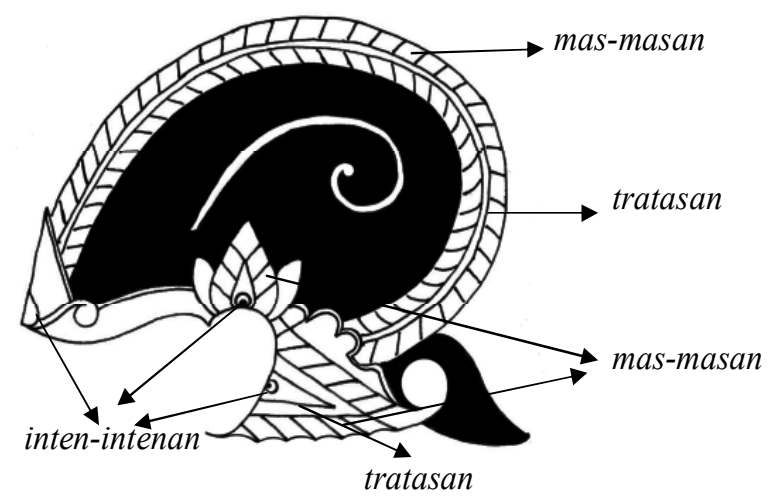

Gambar 2

Contoh motif tatahan dalam wayang golek Menak Yogyakarta (Gambar: Dewanto Sukistono, 2009)

Teknik tatahan wayang kulit purwa juga terkandung dua pengertian, yaitu tentang tingkatan kualitas dan jenis kegiatan. Tingkatan kualitas tatahan pada wayang kulit purwa dapat dibagi menjadi lima kategori, yaitu tatahan kasar, tatahan agal, tatahan ngrawit, tatahan wijang, serta tatahan alus. Tatahan kasar adalah tatahan yang tidak sesuai dengan kaidah yang ada, sebagai contoh pada wayang kelompok putren ditatah dengan tatahan sebesar kelompok bambangan. Tatahan agal artinya tatahan yang serba besar, kurang lengkap, tetapi tetap memperhatikan bentuk gambar masing-masing busana. Tatahan ngrawit disebut 
juga tatahan ngremit yaitu tatahan yang serba kecil atau lembut. Tatahan wijang adalah tatahan yang serba luwes dan lengkap dalam isian busananya. Tatahan alus adalah tatahan yang serba luwes, wijang artinya masing-masing bentuk busananya jelas, ngremit atau ngrawit, dan keserasian lubang antar motif tatahan diperhatikan dengan seksama (Sagio dan Samsugi, 1991: 158-159).

Teknik tatahan berdasarkan jenis kegiatan secara umum dapat dibedakan menjadi kegiatan nyorèk, ambedhah, serta ndelingi. Nyorèk adalah kegiatan paling awal yaitu membuat pola pada lembaran kulit, ambedhah adalah tindakan memisahkan bentuk wayang yang telah digambar dari kulit yang masih utuh, termasuk dalam pengertian ini adalah ambedhah rai yaitu membentuk muka wayang. Ndelingi adalah menghilangkan sudut atau memperhalus tepi hasil dari pahatan tersebut. Pada umumnya ambedhah rai dalam wayang kulit merupakan kegiatan paling akhir setelah menyelesaikan tatahan pada busana dan perhiasan.

Hal di atas bertolak belakang dengan teknik memahat wayang golek, karena ambedhah rai justru merupakan kegiatan yang paling pertama sebelum memahat irah-irahan dan perhiasan kepala lainnya. Teknik tersebut dilakukan karena dalam teknik memahat kepala wayang golek, lebih mudah merubah bentuk irah-irahan atau perhiasan kepala untuk menyesuaikan bentuk muka, daripada sebaliknya yaitu merubah muka untuk menyesuaikan bentuk irah-irahan.

Di dalam teknik tatahan wayang golek Menak berdasarkan tahapan atau jenis kegiatan adalah lakaran, grabahan, bedhahan, serta sandhangan. Lakaran merupakan proses awal yang dimulai dari pembuatan bakalan (mbakali) berupa semacam balok. Grabahan merupakan proses selanjutnya untuk membentuk bagian leher, garis dahi dan telinga, serta gambaran bagian hiasan kepala yang terdiri dari irah-irahan, jamang, serta sumping. Bedhahan adalah tahapan proses pemahatan muka secara utuh. Tahap terakhir adalah sandhangan yaitu memahat hiasan kepala yang terdiri dari irahirahan, jamang, serta sumping. Sandhangan ini juga dilakukan dengan dua tahap, pertama adalah proses nggepuk yaitu melukiskan pola kemudian memahat hiasan serta bagian-bagiannya, kedua adalah proses mecah atau nggempur yaitu memahat kumis, janggut, dan cambang.
Menurut Sukarno, kekuatan rasa karakter wayang golek agar kelihatan 'hidup' tidak sematamata didasarkan pada bentuk atau ukuran wajah yang ideal, tetapi justru yang tidak ideal atau asimetris, misalnya letak kedua mata yang tidak sejajar dan ukurannya tidak sama, posisi mulut tidak tepat di tengah, lingkar pipi tidak rata dan sebagainya (wawancara, 20 September 2009). Hal ini makin jelas ketika wayang golek tersebut hadir dalam format pertunjukan, dengan dukungan gerak maka akan menghasilkan karakter sesuai yang diinginkan. Lebih detil lagi bahwa diantara bagian wajah tersebut yang paling mampu untuk memberikan kehidupan adalah bagian mata, karena secara tidak sadar ketika melihat wajah wayang golek maka perhatian pertama akan terpusat pada mata.

Bentuk wajah wayang golek Menak dapat diduga meniru wajah topeng yang sudah muncul sebelumnya. Topeng di Jawa secara ikonografis bisa dibedakan menjadi empat wujud ungkap yang sangat berbeda, yaitu: (1) makhluk demonik yang menakutkan; (2) mirip dengan wajah manusia; (3) distilisasi dengan merujuk pada wajah-wajah wayang kulit; (4) bentuk wajah manusia sakit atau cacat (Soedarsono, 1998: 4243). Meskipun demikian terdapat perbedaan yang sangat mendasar antara topeng dan wayang golek dalam konteks pertunjukan. Di dalam topeng bagaimanapun berhasilnya penari dalam menghidupkan karakter tokoh, keberadaannya tidak bisa dihilangkan. Seorang penari topeng jarang sekali mampu membawakan berbagai karakter dalam kualitas yang sama. Berbeda dengan wayang golek, apabila dalang berhasil mengekspresikan gerak dan karakter sampai pada tataran dhalang nuksmèng wayang maka sosok dalang tidak akan kelihatan (manjing), seolah-olah bergerak sendiri tanpa digerakkan dalang. Hal ini terjadi karena dalam pertunjukan topeng, seorang penari tidak mungkin berada dalam dimensi ruang dan waktu yang sama dalam membawakan karakter tokoh yang berbeda. Sebaliknya dalam sebuah pertunjukan wayang golek maka dalang justru dituntut mampu menghidupkan berbagai macam karakter dalam dimensi ruang dan waktu yang sama.

Wanda dalam wayang golek Menak Yogyakarta tidak begitu diperhatikan, menurut Sukarno hanya dikenal satu tokoh yang mempunyai wanda, yaitu 
Umarmaya wanda jangkrik yang mempunyai ciri utama yaitu wajah lebih menengadah dibanding tokoh Umarmaya pada umumnya. Berkaitan dengan Wanda ini Sutrisno menjelaskan:

... kangge nggampilaken titikan wanda wayang punika mriksanana (a) longok saha tumungkuling praupan; (b) kendho lan singseting pawakan; (c) jejeg lan agronging adeg; (d) bedhahan lan praboting wayang; (e) patut empering sunggingan (Sutrisno, 1964:5).

... untuk memudahkan ciri-ciri wanda wayang maka perlu memperhatikan (a) menengadah dan menunduknya raut muka; (b) postur tubuh atau perawakan; (c) posisi berdiri; (d) bedhahan atau bentuk muka wayang dan kelengkapan busana dan perhiasan wayang; (e) sunggingan atau teknik pewarnaan.

Besar kecilnya ukuran masing-masing tokoh wayang tidak ada pembakuan karena hanya berdasarkan perkiraan dan selera, bahkan kadangkadang tokoh wayang dalam dimensi ruang dan waktu yang sama bisa saja tampil dalam variasi bentuk yang berbeda, baik dari postur maupun perabot perhiasannya. Contoh dalam hal ini adalah Prabu Nusirwan, seorang raja dari negara Medayin selain menggunakan irah-irahan topong juga bisa menggunakan mekutha nyamat. Begitu pula kadang satu badan yang sama bisa digunakan untuk kepala yang berbeda, atau sebaliknya badannya berbeda tetapi kepalanya sama, misalnya yang semula berperut rata berganti dengan berperut buncit.

Sunggingan dalam wayang golek Menak Yogyakarta mempunyai ciri khusus seperti dalam wayang kulit yaitu teknik gradasi atau tingkatan warna tertentu. Sunggingan dalam wayang golek hanya dilakukan khususnya pada bagian kepala, yaitu bagian muka atau disebut ulat-ulatan dan tutup kepala atau irah-irahan beserta kelengkapannya yaitu jamang dan sumping. Motif yang digunakan adalah meniru motif sunggingan pada wayang kulit purwa meskipun bentuknya lebih sederhana. Beberapa motif sunggingan yang digunakan dalam wayang golek Menak Yogyakarta adalah: tlacapan, kelopan, cawèn, balesan, drenjeman, bludiran, isènisèn, serta mas-masan. Tlacapan berbentuk lanciplancip, biasanya ditemukan pada irah-irahan, jamang dan sumping. Tlacapan yang ukurannya

lebih kecil biasa disebut dengan sawutan untuk bidang yang lebih kecil. Kelopan pada wayang golek berfungsi untuk mengisi bidang yang lebih luas dengan mengikuti bentuk tatahan. Cawèn adalah memberikan ornamen garis-garis kecil pada motif tlacapan, sawutan, dan kelopan. Garisgaris ini berfungsi untuk mempertegas efek warna agar kelihatan lebih jelas. Balesan adalah berupa garis hitam yang berfungsi untuk mempertegas batas warna antara bagian yang satu dengan bagian yang lain agar bentuknya menjadi lebih jelas, karena gradasi warna paling luar adalah warna yang paling terang. Drenjeman, adalah isian berupa titik-titik hitam yang ditempatkan di atas kombinasi warna-warna merah, hijau, oranye (kapuranta), biru, serta ungu (mronggèng). Kombinasi warna yang diberi motif drenjeman adalah terutama pada mas-masan. Bludiran adalah motif sunggingan berwarna hitam pada umumnya berupa bunga lengkap dengan daunnya dalam berbagai bentuk. Motif ini biasanya ditempatkan pada hiasan atau tutup kepala berupa udheng gilig, sorban kéyongan, atau iket udharan. Isèn-isèn adalah hiasan yang berupa perpaduan ornamen garis maupun lingkaran dengan motif bebas untuk mengisi warna-warna tertentu, baik dalam bentuk blok atau gradasi. Sama halnya dengan bludiran, isèn-isèn pada umumnya berwarna hitam untuk semua dasar warna yang ditumpanginya. Mas-masan adalah khusus untuk mengisi bidang pada tatahan mas-masan. Motif ini merupakan kombinasi dari gradasi warna hijau pada pangkal dan merah pada ujungnya dalam satu bidang. Peralihan antara warna hijau dengan warna merah biasanya warna putih. Sunggingan mas-masan akan selalu ditumpangi dengan drenjeman yang merupakan hiasan titik-titik hitam, maupun cawèn yang berupa hiasan garis-garis berwarna hitam untuk memunculkan kesan gemerlap.

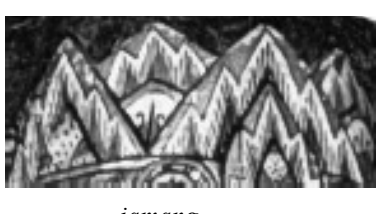

jamang

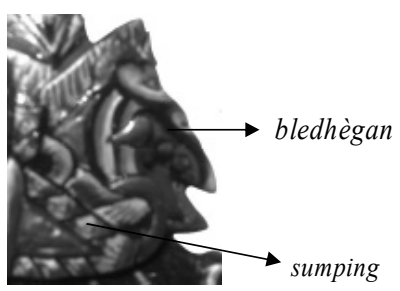

Gambar 3

Contoh motif sunggingan pada jamang, sumping dan bledhègan (Foto; Dewanto Sukistono, 2009) 
Sunggingan dalam wayang golek Menak pada masa sekarang menggunakan bahan utama cat air modern dan bukan cat minyak. Jenis yang digunakan adalah acrylic, movilex atau poster colour berbagai warna untuk warna sunggingannya, serta bahan brom untuk warna emas. Pada saat pengenceran acrylic atau poster colour dicampur dengan sedikit lem kayu agar cat lebih melekat kuat, pada masa sekarang jenis yang cukup praktis dan modern adalah lem PVA atau polyvinil Asetat yang biasanya berbentuk kemasan cairan yang sangat kental. Sebelum disungging maka perlu diberi warna dasar putih terlebih dahulu dengan bahan cat tembok atau bisa juga acrylic.

Beberapa warna yang biasa dipergunakan adalah hitam, putih, merah, oranye (kapuranta), hijau, kuning, biru, ungu (mronggèn), dan warna emas atau brom. Sepanjang pengamatan Ki Sukarno dan pengalamannya sampai saat ini Ki Widiprayitna belum pernah menggunakan prada mas atau prada plastik untuk warna emas karena rumit dan harganya jauh lebih mahal. Gradasi atau tingkatan warna biasanya paling banyak tiga tingkatan dengan perbedaan warna kontras.

Warna hitam yang digunakan terdiri dari dua macam sesuai dengan penggunaannya, yaitu berbahan acrylic, movilex atau poster colour untuk warna rambut maupun warna irah-irahan atau bidang lain yang memerlukan blok warna hitam dipoles dengan menggunakan kuas. Selain acrylic atau poster colour digunakan tinta cina atau bahan pigment inklencre a pigment tahan air (waterproof). Warna hitam dengan tinta ini khusus untuk membuat cawén yang berupa garis-garis, drenjeman berupa titik-titik, maupun isèn-isèn atau hiasan berbagai motif. Tinta ini ditorehkan dengan menggunakan pena atau drawing pen berbagai ukuran yang lebih praktis dan modern.

Warna putih terdiri dari dua macam sesuai dengan kebutuhan, yaitu pertama untuk warna dasar sebelum disungging serta warna putih untuk sunggingan. Warna dasar tidak diperlukan untuk bagian yang akan diberi warna emas atau brom, seperti bagian leher serta tangan. Warna putih dalam sunggingan biasanya berfungsi untuk mempertegas batas gradasi dari dua warna, seperti pada sunggingan mas-masan. Selain itu juga ditempatkan di akhir atau ujung dari gradasi warna apapun sebagai warna yang paling terang, karena gradasi warna dalam sunggingan selalu diawali dengan warna gelap di pangkal serta warna terang di ujung. Warna putih sebagai sunggingan misalnya sebagai warna dasar wajah tokoh-tokoh tertentu, selain warna-warna lain sesuai dengan kebutuhan.

Warna merah dalam sunggingan termasuk warna yang dominan. Warna ini bisa ditemukan di hampir semua bagian kepala wayang, baik pada tatahan sandhangan yang berupa hiasan kepala seperti irah-irahan, jamang, serta sumping. Di dalam bagian tersebut warna merah selalu ditempatkan di ujung mas-masan serta sebagian inten-intenan. Warna merah juga biasa dapat ditemukan pada warna bibir, tlacapan, kelopan, warna dasar wajah tokoh-tokoh tertentu, dan lain sebagainya.

Warna kapuranta merupakan hasil dari pencampuran warna jingga atau oranye yang merupakan pencampuran warna kuning dan merah, yang ditambah dengan sedikit warna putih. Warna ini biasanya merupakan tingkatan gradasi warna yang terdapat pada mas-masan, serta sebagian inten-intenan. Selain itu warna ini juga kadang-kadang ditempatkan pada tutup kepala sebagai blok warna, kemudian diisi dengan isén-isén.

Warna hijau paling banyak ditempatkan sebagai perpaduan atau kombinasi dari mas-masan serta sebagian inten-intenan. Warna ini termasuk warna yang kuat dan tidak mudah untuk dikombinasikan dengan warna lain. Sebagian besar warna ini dikombinasikan dengan warna merah karena transisi warnanya yaitu warna kuning sangat dekat dengan warna merah.

Warna biru biasanya ditempatkan pada sebagian kenthawala, inten-intenan, sebagian gelapan atau bledhègan, dan beberapa bidang lain. Warna ini juga sering dikombinasikan dengan warna merah untuk bentuk tlacapan dan kelopan, atau pada bagian sayap burung.

Warna ungu (mronggèn) merupakan hasil dari pencampuran warna merah jambu dengna warna biru, biasanya dikombinasikan dengan warna kapuranta yang ditempatkan pada hiasan inten-intenan, atau bisa juga sebagai warna dasar atau blok warna untuk tutup kepala yang dihias dengan isèn-isèn.

Warna emas dalam wayang golek Menak Yogyakarta jarang sekali menggunakan bahan emas atau yang biasa disebut prada mas, tetapi 
menggunakan bahan brom. Bahan ini berupa serbuk berwarna keemasan, bisa dilarutkan dengan lem PVA atau polyvinil Asetat, tetapi bisa juga dilartukan dengan menggunakan vernis. Pengenceran dengan menggunakan bahan vernis biasanya warnanya kelihatan lebih gelap atau dop, sedangkan apabila diencerkan dengan menggunakan lem polyvinil Asetat warnanya akan lebih terang memancar atau gilap. Pemberian warna brom ini dilakukan sesudah kepala golek tersebut di-dus atau dilapisi vernis agar tahan lama, karena kalau brom tersebut dilapisi vernis akan pudar dan kehitam-hitaman tidak bisa memancar atau gemerlap. Warna brom ini ditempatkan pada sebagian hiasan, tetapi sebagai warna blok biasa ditempatkan pada leher sampai di bawah dagu, serta untuk warna tangan dan perut apabila dalam keadaan terbuka.

\section{Busana wayang}

Tata busana dalam wayang golek Menak yang paling utama terdiri dari baju untuk bagian atas serta kain atau jarit untuk bagian bawah. Selain itu untuk tokoh-tokoh tertentu biasanya ditambah dengan kelengkapan lain, seperti keris, sampur, maupun perhiasan. Jenis kain untuk baju sebagain besar menggunakan bahan beludru yang diberi hiasan berbahan motte dengan motif disesuaikan dengan tokoh yang menggunakannya, biasanya dari kalangan kerajaan.

Kain atau jarit untuk kalangan istana biasanya menggunakan kain batik berbagai motif sesuai dengan tokohnya, misalnya seorang raja menggunakan kain batik motif parangrusak. Kain atau jarit tersebut selama ini tidak pernah memesan khusus untuk kebutuhan wayang golek, artinya motif batik dibuat ukuran yang lebih kecil sesuai dengan ukuran ideal wayang. Sukarno mengakui bahwa banyak dari tokoh yang sebenarnya tidak tepat dalam pemakaian motif batik sesuai dengan kedudukannya, kecuali untuk tokoh raja selalu menggunakan motif parangrusak. Kain atau jarit ini di bagian belakang sengaja diberi sedikit belahan agar tangan dalang lebih leluasa dalam memegang wayang, dan posisi kain tersebut dari depan tetap utuh tidak menggulung.

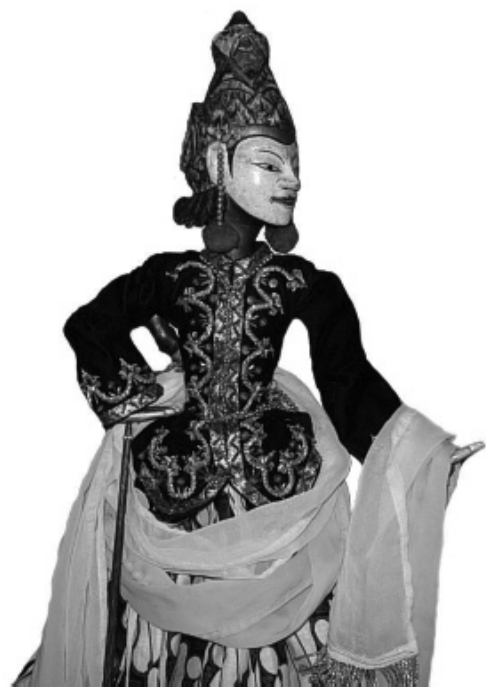

Gambar 4

Contoh busana tokoh Wongagung Jayengrana lengkap dengan sampur dan kerins di pinggangnya (Foto: Dewanto Sukistono, 2009)

\section{Penutup}

Wayang golek Menak adalah salah satu jenis wayang golek yang berbentuk tiga dimensi dan menggunakan Serat Menak yang bernafaskan Islam sebagai sumber utama lakon. Selain wayang golek Menak, di Indonesia terdapat beberapa macam wayang golek dengan sumber cerita yang berbeda-beda dan dengan gayanya masingmasing. Di Yogyakarta dan sekitarnya wayang golek biasa disebut dengan istilah wayang Thengul, dipopulerkan oleh Ki Widiprayitna atau Ki Regut hingga mengalami masa-masa kejayaan sekitar tahun 1950-an. Berdasarkan perbedaan sumber cerita tersebut, tentu saja bentuk wayangnya juga berbeda-beda, termasuk dalam tatahan dan sunggingan serta busana wayang sebagai salah satu dimensi estetika bentuk wayang.

Pembahasan tentang tatahan maka akan terkandung dua pengertian, yaitu persoalan motif dan teknik tatahan. Motif tatahan wayang golek Menak mengacu pada motif tatahan wayang kulit purwa, hanya bentuknyalebih sederhana dan secara umum hanya menggunakan empat macam motif yang disebut pecahan, yaitu mas-masan, intenintenan, tratasan, serta seritan. Meskipun motif tatahan wayang golek mengacu pada wayang kulit purwa tetapi secara bentuk jelas berbeda, karena tatahan wayang kulit purwa akan menghasilkan lubang-lubang yang menggambarkan tingkat kerumitan dan keindahannya, baik secara langsung 
maupun yang terungkap lewat bayangan di kelir. Tatahan pada wayang golek tidak menghasilkan lubang, motifnya lebih sederhana karena hanya berfungsi untuk memberikan ruang pada motif warna atau sunggingannya saja, oleh karena itu detail bentuknya tidak terlalu dominan.

Di dalam pembicaraan tentang teknik tatahan wayang kulit purwa terkandung dua pengertian, yaitu tentang tingkatan kualitas dan jenis kegiatan. Tingkatan kualitas tatahan pada wayang kulit purwa dapat dibagi menjadi lima kategori, yaitu tatahan kasar, tatahan agal, tatahan ngrawit, tatahan wijang, serta tatahan alus.

Teknik tatahan berdasarkan jenis kegiatan secara umum dapat dibedakan menjadi kegiatan nyorèk, ambedhah, serta ndelingi.

Fungsi tatahan dalam wayang golek adalah terutama untuk membuat bidang sunggingan, oleh karena itu tingkatan kualitasnya pada umumnya masuk dalam kategori tatahan agal seperti dalam tatahan wayang kulit. Teknik tatahan wayang golek Menak berdasarkan tahapan atau jenis kegiatan adalah lakaran, grabahan, bedhahan, serta sandhangan. Lakaran merupakan proses awal yang dimulai dari pembuatan bakalan (mbakali) berupa semacam balok. Grabahan merupakan proses selanjutnya untuk membentuk bagian leher, garis dahi dan telinga, serta gambaran bagian hiasan kepala yang terdiri dari irah-irahan, jamang, serta sumping. Bedhahan adalah tahapan proses pemahatan muka secara utuh. Tahap terakhir adalah sandhangan yaitu memahat hiasan kepala yang terdiri dari irah-irahan, jamang, serta sumping. Sandhangan ini juga dilakukan dengan dua tahap, pertama adalah proses nggepuk yaitu melukiskan pola kemudian memahat hiasan serta bagian-bagiannya, kedua adalah proses mecah atau nggempur yaitu memahat kumis, janggut, dan cambang.

Sunggingan dalam wayang golek Menak Yogyakarta mempunyai ciri khusus seperti dalam wayang kulit yaitu teknik gradasi atau tingkatan warna tertentu. Sunggingan dalam wayang golek hanya dilakukan khususnya pada bagian kepala, yaitu bagian muka atau disebut ulatulatan dan tutup kepala atau irah-irahan beserta kelengkapannya yaitu jamang dan sumping. Motif yang digunakan adalah meniru motif sunggingan pada wayang kulit purwa meskipun bentuknya lebih sederhana. Beberapa motif sunggingan yang digunakan dalam wayang golek Menak Yogyakarta adalah: tlacapan, kelopan, cawèn, balesan, drenjeman, bludiran, isèn-isèn, serta masmasan.

Sunggingan dalam wayang golek Menak pada masa sekarang menggunakan bahan utama cat air modern dan bukan cat minyak. Jenis yang digunakan adalah acrylic, movilex atau poster colour berbagai warna untuk warna sunggingannya, serta bahan brom untuk warna emas. Pada saat pengenceran acrylic atau poster colour dicampur dengan sedikit lem kayu agar cat lebih melekat kuat, pada masa sekarang jenis yang cukup praktis dan modern adalah lem PVA atau polyvinil Asetat yang biasanya berbentuk kemasan cairan yang sangat kental. Sebelum disungging maka perlu diberi warna dasar putih terlebih dahulu dengan bahan cat tembok atau bisa juga acrylic. Beberapa warna yang biasa dipergunakan adalah hitam, putih, merah, oranye (kapuranta), hijau, kuning, biru, ungu (mronggèn), dan warna emas atau brom.

Tata busana dalam wayang golek Menak yang paling utama terdiri dari baju untuk bagian atas serta kain atau jarit untuk bagian bawah. Selain itu untuk tokoh-tokoh tertentu biasanya ditambah dengan kelengkapan lain, seperti keris, sampur, maupun perhiasan. Jenis kain untuk baju sebagian besar menggunakan bahan beludru yang diberi hiasan berbahan motte dengan motif disesuaikan dengan tokoh yang menggunakannya, biasanya dari kalangan kerajaan. Bahan lurik atau jenis yang lain dipakai untuk tokoh-tokoh di luar kalangan istana, seperti, abdi, panakawan, buto babrah dan sebagainya. Kain atau jarit untuk kalangan istana biasanya menggunakan kain batik berbagai motif sesuai dengan tokohnya, misalnya seorang raja menggunakan kain batik motif parangrusak. Kain atau jarit ini di bagian belakang sengaja diberi sedikit belahan agar tangan dalang lebih leluasa dalam memegang wayang.

\section{Kepustakaan}

Brandon, James R. 2003. Jejak-jejak Seni Pertunjukan di Asia Tenggara diterjemahan R.M. Soedarsono. Bandung: P4ST UPI

Currell, David. 1974. The Complete Book of Puppetry. Great Britain: Pitman Publishing. 
Fang, Liaw York. 1982. Sejarah Kesusastraan Melayu Klasik. Singapura: Pustaka Nasional PTE LTD.

Haryono, Timbul. 2004. Seni Pertunjukan Pada Masa Jawa Kuno. Yogyakarta: Pustaka Raja.

Holt, Claire. 2000. Melacak Jejak Perkembangan Seni di Indonesia. Diterjemahkan oleh R.M. Soedarsono. Bandung: Masyarakat Seni Pertunjukan Indonesia.

Istanti, Kun Zachrun. 2005. "Hikayat Amir Hamzah: Suntingan Teks dan Telaah Resepsi", [Disertasi]. Yogyakarta: Program Studi Ilmu Sastra Universitas Gadjah Mada.

Kamajaya. 1986. Serat Centhini. Yogyakarta: Centhini.

Kayam, Umar. 2001. Kelir Tanpa Batas. Yogyakarta: Gama Media untuk Pusat Studi Kebudayaan Universitas Gadjah Mada.

Kuardhani, Hirwan. 2011. Toni Harsono Maecenas Potehi dari Gudo Yogyakarta: Isacbook.

Kusumadilaga, K.P.A. 1930. Pakem Sastramiruda Solo: De Bliksem.

Mardiwarsito, L. 1978. Kamus Jawa Kuna (Kawi)Indonesia. Jakarta: Nusa Indah Ende.

Pigeaud, Theodore G.Th. 1938. Javaanse Volksvertoningen. Batavia: Volkslectuur.

Poerwadarminta, W.J.S. 1939. Baoesastra Djawa. Batavia: B. Uitgevers-Maatschappij N.V. Groningen.
1983. Kamus Umum Bahasa Indonesia.

Jakarta: Balai Pustaka.

Sagio dan Samsugi, 1991. Wayang Kulit Gagrag Yogyakarta. Jakarta: CV Haji Masagung.

Soedarsono, R.M. 1997. Wayang Wong, Drama Tari Ritual Kenegaraan di Keraton Yogyakarta. Yogyakarta: Gadjah Mada University Press. . 1998. "The Mask and Characterization System," dalam Edi Sedyawati, et al.,ed., Indonesian Heritage: Performing Arts. Singapore: Archipelago Press, 1998.

Snelleman, 1905. Encyclopaedie van Nederlansch Old Indie. Leiden: E.J. Bril.

Sutrisno, R. 1964. Pitakonan lan Wangsulan Bab Wanda Wayang Purwo. Cetakan I. Surakarta: CV Mahabarata.

Tohir, Muhammad. 1979. Sejarah Islam dari Andalus sampai Indus. Jakarta: Pustaka Jaya.

Wiessner, Polly. 1993. "Style and Social Information in Kalahari San Projectile", dalam American Antiquity Volume 48 No. 42.

\section{Informan}

Sukarna, 63 tahun. Seniman Dalang. Sentolo, Kulon Progo. 